\title{
Geographic variation in the acoustic signals of black-billed magpies (Pica pica) in South Korea and Japan
}

\author{
Sang-im Lee ${ }^{1,2}$, Sunhee Lee ${ }^{2,3}$, Hyun-Young Nam ${ }^{2,4}$ and Jae Chun Choe ${ }^{3, *}$ \\ ${ }^{1}$ Institute of Advanced Machinery and Design, Seoul National University, Seoul 151-742, Korea \\ ${ }^{2}$ Laboratory of Behavioral Ecology and Evolution, Department of Biological Sciences, Seoul National University, Seoul 151-742, Korea \\ ${ }^{3}$ Laboratory of Behavior and Ecology, Division of Ecoscience, Ewha Womans University, Seoul 120-750, Korea \\ ${ }^{4}$ Migratory Birds Center, National Park Research Institute, Jeonnam 535-917, Korea
}

\begin{abstract}
Black-billed magpies (Pica pica) are a highly sedentary species due to their short and round wings, which are not adequate for long distance flights. We investigated geographic variation in the vocal signals of magpies residing in South Korea and Japan (subspecies sericea). Based on the magpie's limited dispersal ability, we predicted that the variation in vocal signals of black-billed magpies could be explained by geographic barriers such as mountain ranges and straits. We analyzed four-syllable chatter calls of magpies from five localities in South Korea, which are separated by mountain ranges (Seoul, Daejeon, Daegu, Gwangju, and Busan), and two island localities separated from the mainland by straits (Jeju in Korea and Saga in Japan). We found significant differences in the characteristics of magpie chatter calls recorded in the seven localities, and the variation pattern was independent among the variables. Mainland-island differentiation and north-south differentiation were observed. In general, magpies on Saga were the most distinctive. North-south differentiation was observed among the Korean mainland localities. However, the pattern was not related to the presence of putative geographic barriers. We hypothesize that the patterns of geographic variation in the structure of magpie chatter calls residing in South Korea might have been shaped by a sudden expansion of magpies followed by low level of local isolation, which may have led to vocal differentiation. Along with elucidating the vocal environment of Korean magpie populations, more extensive sampling is needed to clarify the functional aspects of geographic variation in the vocal signals of Korean magpies.
\end{abstract}

Key words: geographic barriers, geographic variation, chatter call, Pica pica, vocal signals

\section{INTRODUCTION}

Acoustic signals are the most important communication vehicle for birds. In early reports, vocal learning was seen as a special adaptation, but as a remarkable variety of learning processes have been revealed, vocal cultures have come to be known as the largest body of evidence for cultural transmission of behavioral traits (Laland and Janik 2006). Vocal learning has been documented in only three distantly related groups of birds: parrots, hummingbirds, and songbirds (Jarvis 2004). Learning involves imitation, but imperfect learning may lead to variation and differentiation in vocal signals (Krebs and Kroodsma 1980), just as mutation and divergence in genetic evolution. Geographic variation in acoustic signals is a common feature among songbirds. Dialects that form

\section{Open Access DOI: 10.5141/JEFB.2011.019}

This is an Open Access article distributed under the terms of the Creative Commons Attribution Non-Commercial License (http://creativecommons org/licenses/by-nc/3.0/) which permits unrestricted non-commercial use distribution, and reproduction in any medium, provided the original work is properly cited. pISSN: 1975-020X eISSN: 2093-4521
Received 07 October 2010, Accepted 04 January 2011

*Corresponding Author

E-mail: jaechoe@ewha.ac.kr

Tel: +82-2-3277-4512 
a mosaic pattern of local clusters have been documented mainly in the male courtship songs of songbirds (Marler and Tamura 1964, Tubaro et al. 1993, MacDougallShackleton and MacDougall-Shackleton 2001, Baker and Logue 2003, Kroodsma 2005). Geographic variation in the routine calls of parrots (Bradbury et al. 2001, Wright and Wilkinson 2001, Kleeman and Gilardi 2005) and in those of crow species (Enggist-Dueblin and Pfister 2002, Laiolo and Rolando 2003) have been described as well.

Corvids are one of the most intelligent birds, with a significantly large forebrain analogous to the mammalian prefrontal cortex and they demonstrated superior intelligence like apes (Emery and Clayton 2004). Because cultural evolution is dependent on cognitive abilities, corvids have been included in many recent studies about animal culture (Chappell and Kacelnik 2002, EnggistDueblin and Pfister 2002 for vocal cultural evolution, Hunt and Gray 2003). The basic feature that enables geographic variation in vocal traits is that vocal signals are learned, and there is some, albeit not as extensive as other songbirds, evidence that vocal signals of corvids are learned (Webber and Stefani 1990). Considering their highly developed cognitive abilities, we expect that the rate of vocal differentiation in corvids is faster than that of other birds, resulting in geographic variation in vocal signals, even in regions with relatively short periods or low levels of isolation. The magpies (genus Pica) are members of Corvidae, but geographic variations in their vocal signals have been rarely studied in detail, despite their global distribution.

In this study, we analyzed the geographic distribution of vocal patterns in black-billed magpies (Pica pica sericea) in Korea and Japan. Black-billed magpies have relatively short dispersal distances, probably due to their short and round wings (Goodwin 1986, Birkhead 1991). They are not expected to be able to fly across high mountains or straits, and they rarely reside on islands. Jeju (Korea) and Saga (Japan), near the Korean peninsula, are the closest island habitats in which magpies are found. These two populations were founded through a series of human introductions to Jeju in 1989 (Koo 1994) and to Saga approximately 400 years ago (Eguchi and Kubo 1992). Considering that cultural transmission and associated vocal learning can be hampered by geographic barriers such as high mountains and straits, we aimed to investigate whether (i) variation in magpie vocal signals could be explained by geographic barriers; and (ii) vocal signals of two introduced island populations are more distinct than those of mainland populations.

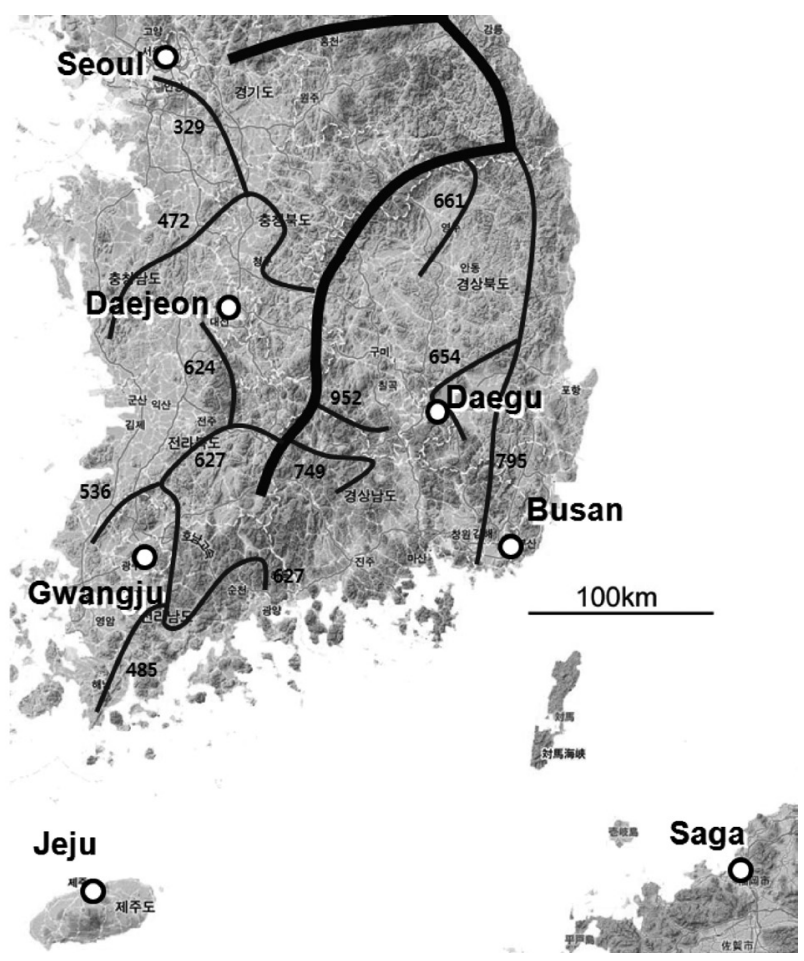

Fig. 1. Sampling sites used in this study. Thick line represents the main mountain range bisecting the Korean peninsula (Baekdudaegan, average height: 1,248 m) and the thin lines represent secondary mountain ranges (adopted from Kim et al. 2004). Numbers shown near the thin lines are the average height of the secondary mountain ranges. Recording dates were May $9^{\text {th }}, 16^{\text {th }}$, and $23^{\text {rd }}$ for Seoul, April $19^{\text {th }}$ and $20^{\text {th }}$ for Daejeon, April $2^{\text {nd }}$ and May $6^{\text {th }}$ for Daegu, April $8^{\text {th }}$ and $9^{\text {th }}$ for Gwangju, March $19^{\text {th }}$ and $20^{\text {th }}$ for Busan, March $15^{\text {th }}$ and $25^{\text {th }}$ for Jeju, and April $16^{\text {th }}$ and $18^{\text {th }}$ for Saga. Map was taken from Google Earth.

\section{MATERIALS AND METHODS}

\section{Recording}

We recorded the chatter calls of magpies. Chatter calls are the most frequently produced calls throughout the year and can be distinguished easily by humans (Birkhead 1991). Chatter calls are used as a general alarm, and are mostly produced in the presence of intruders. We recorded chatter calls from March to May 2006. During this period, magpies defended their territory vigorously and produced chatter calls more frequently than during other periods. We recorded magpie calls from seven localities (Fig. 1): in South Korea, Seoul (N $37^{\circ} 30^{\prime}$, E $127^{\circ} 00^{\prime}$ ), Daejeon (N $\left.36^{\circ} 20^{\prime}, \mathrm{E} 127^{\circ} 26^{\prime}\right)$, Daegu (N $35^{\circ} 52^{\prime}, \mathrm{E}$ $128^{\circ} 35^{\prime}$ ), Busan (N $35^{\circ} 06^{\prime}$, E $129^{\circ} 03^{\prime}$ ), Gwangju (N $35^{\circ} 09^{\prime}$, E $\left.126^{\circ} 54^{\prime}\right)$; and Jeju island (N 33 $31^{\prime}$, E $\left.126^{\circ} 32^{\prime}\right)$; and on Saga (N $33^{\circ} 16^{\prime}$, E $130^{\circ} 18^{\prime}$ ) Japan. Saga, on the island of Kyushu, is the location where wild magpies from Korea 


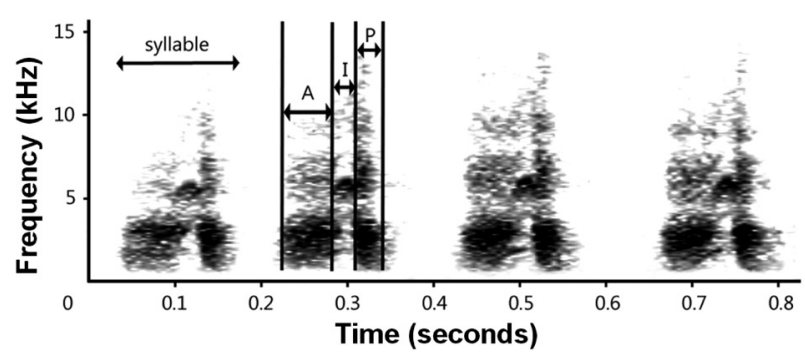

Fig. 2. Structure of a typical chatter call with four syllables. We divided the syllables into three parts for analysis: anterior (A), inflection (I), and posterior parts $(\mathrm{P})$.

were originally introduced (Eguchi and Kubo 1992). Jeju and Saga are separated from mainland localities (Seoul, Daejeon, Daegu, Gwangju, and Busan) by the sea.

In our study, vocal signals recorded from unmarked individuals were used. However, as we sampled during the breeding season, magpie activity was confined around the nest, and the birds defended their territories vigorously. Thus, we could minimize the chance of treating recordings from several individuals as those from one individual. We recorded $10 \mathrm{~min}$ at one territory and moved to adjacent territories to sample multiple individuals. Chatter calls invoked by the appearance of predators or by an intrusion of neighboring magpies were not analyzed. Vocal signals of 137 individuals were analyzed: 25 in Seoul, 23 in Daejeon, 22 in Daegu, 24 in Gwangju, 18 in Busan, 21 on Jeju, and four on Saga.

\section{Sampling procedure}

The vocalizing birds were recorded from a distance of about $10 \mathrm{~m}$ using a Sennheiser MKH70-P48 shotgun condenser microphone mounted on a Tascam DA-P1 or a Tascam HD-P2 digital recorder. When necessary, we digitized the recordings at a $44.1 \mathrm{kHz}$ sampling rate and 16 bit resolution in Windows PCM through a sound analysis software Raven ver. 1.2 (Cornell Laboratory of Ornithology, Ithaca, NY, USA). The same software was used to generate spectrograms with an option of 512 points Hann window, $124 \mathrm{~Hz}$ bandwidth, 50\% overlap, 256 points time grid, $86.1 \mathrm{~Hz}$ frequency grid, and 512 points DFT.

Typical chatter calls of magpies consist of 2-30 syllables. Because the number of syllables may depend on the contexts in which the calls were produced, we limited our analyses to chatter calls with four syllables. Each syllable was characterized by anterior, inflection, and posterior parts (Fig. 2). From the spectrogram, we extracted the duration of anterior, inflection and posterior parts ("Da",
"Di", and "Dp", respectively) and the dominant frequency of each part ("Fa", "Fi", and "Fp", respectively). Additionally, we calculated the ratio between the durations of inflection and anterior parts of each syllable ("Di/Da”), and the ratio between the dominant frequency of anterior and inflection parts ("Fa/Fi”). Except for the last syllable of a call, we also measured the time gap to the next syllable (interval). Specifying the beginning and the end of parts (anterior, inflection, and posterior parts) as well as those of syllables was done manually by comparing the waveform of the syllables and considering the energy concentration. We did not include parts with weak signals, as these parts are less likely to operate as proper signals that convey information and were possibly present due to background noise or call reverberation.

\section{Statistical analyses}

We used general linear mixed models (GLMM) to investigate geographic variations in call structure among the localities. Each syllable was analyzed separately. Post-hoc comparisons on the least square means were conducted with Tukey-Kramer corrections. Because several calls were recorded from one individual and 1 day of recording contained many individuals, we treated the recording date and individual as blocks for analyses.

We also conducted principal component analysis to examine grouping patterns of individuals. After retrieving factor scores for the principal components, we conducted GLMMs to examine the patterns of variation in vocal signals, in a similar way as the analyses of the raw data.

Cluster analyses were conducted to summarize the patterns of geographic variation in the chatter calls. Because raw data contained hierarchical data structure, we used least square means calculated from the GLMMs on the principal components. Euclidean distances were calculated, and the complete linkage method was used. All statistical analyses were conducted with SAS ver. 9.1 (SAS Institute, Cary, NC, USA).

\section{RESULTS}

We found significant differences in the characteristics of magpie chatter calls recorded from the seven localities (Table 1). Both temporal traits (except for the interval between the syllables) and frequency-related traits varied geographically, although the pattern of variation was independent among the variables. We categorized 

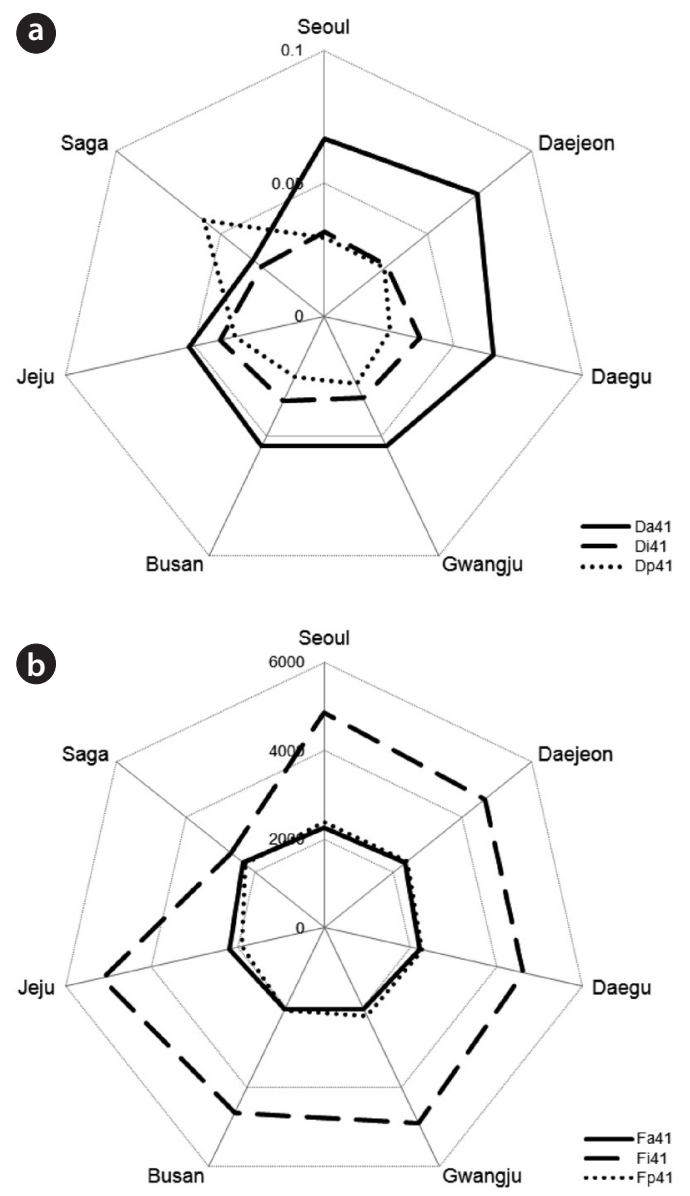

Fig. 3. Polar charts showing the variation in the mean values of chatter call traits; temporal traits (units: seconds) (a) and frequency-related traits (units: $\mathrm{Hz}$ ) (b). Only the mean values of the first syllable of four-syllable chatter calls (noted as " 41 ") are shown. $\mathrm{Da}, \mathrm{Di}, \mathrm{Dp}$, duration of anterior, inflection, and posterior parts; $\mathrm{Fa}, \mathrm{Fi}$, Fp, dominant frequencey of anterior, inflection, and posterior parts. the patterns of variation into five types; (I) differentiation between northern (Seoul and Daejeon) and southern localities (Daegu, Gwangju, Busan, Jeju, and Saga); (II) north-south differentiation, in which Daegu was similar to northern localities; (III) north-south differentiation, except Saga, which was similar to northern localities; (IV) mainland-island differentiation; and (V) north-south and mainland-island differentiation. Most of the vocal parameters showed consistent variation patterns regardless of syllables. Magpies on Saga were generally the most distinctive (categories IV and V), and vocal differentiation among Korean magpies was low except for the Jeju population. A north-south differentiation was observed for the vocal traits that showed differentiation among Korean magpies.

We plotted the least square means as polar charts (Fig. 3 ). We present the results from the first syllable only, as the variation patterns for other syllables were similar. The general pattern for temporal traits was $\mathrm{Da}>\mathrm{Di}>\mathrm{Dp}$, except for Seoul and Daejeon where $\mathrm{Dp}>\mathrm{Di}$, and Saga where Dp $>$ Da $>$ Di (Fig. 3a). For the frequency-related traits, Fa was similar to Fp, and Fi was higher than both (Fig. 3b). Chatter calls from northern localities (Seoul, Daejeon, and Daegu) were characterized by a longer Da and a higher Fa and Fp. Call characteristics of Saga magpies were the most distinguished from others by having a longer Dp and a lower Fi. Fi was similar to Fa and Fp in the calls of Saga magpies, so their calls had a fairly constant dominant frequency.

We obtained three principal components (PCs) which accounted for $29.2,26.8$, and $14.9 \%$ of the total variance,

Table 1. Results from the general linear mixed models

\begin{tabular}{|c|c|c|c|c|c|c|c|c|}
\hline \multirow{3}{*}{$\begin{array}{l}\text { Variables } \\
\mathrm{Da}\end{array}$} & \multicolumn{8}{|c|}{ Four-syllable chatter calls } \\
\hline & \multicolumn{2}{|l|}{$1^{\mathrm{st}}$} & \multicolumn{2}{|l|}{$2^{\text {nd }}$} & \multicolumn{2}{|l|}{$3^{\text {rd }}$} & \multicolumn{2}{|l|}{$4^{\text {th }}$} \\
\hline & $6.45^{* * *}$ & II & $4.40^{* * *}$ & II & $3.64^{* *}$ & $\mathrm{I}$ & $2.44^{*}$ & $\mathrm{I}$ \\
\hline Di & $3.89^{* *}$ & I & $4.38^{* * *}$ & I & $2.02^{\mathrm{NS}}$ & & $4.25^{* * * *}$, & I \\
\hline $\mathrm{Dp}$ & $7.77^{* * *}$ & IV & $7.04^{* * * *}$ & IV & $4.60^{* * *}$ & $\mathrm{~V}$ & $4.08^{* * *}$, & IV \\
\hline $\mathrm{Di} / \mathrm{Da}$ & $18.25^{* * * *}$ & IV & $5.95^{* * * *}$ & IV & $6.86^{* * *}$ & IV & $4.88^{* * *}$, & IV \\
\hline $\mathrm{Fa}$ & $1.22^{\mathrm{NS}}$ & & $3.22^{* *}$ & II & $1.92^{\mathrm{NS}}$ & & $2.56^{*}$ & III \\
\hline $\mathrm{Fi}$ & $6.66^{* * *}$ & IV & $4.28^{* * *}$ & $\mathrm{~V}$ & $3.06^{* *}$ & $\mathrm{~V}$ & $3.52^{* *}$ & $\mathrm{~V}$ \\
\hline $\mathrm{Fp}$ & $5.69^{* * * *}$ & III & $3.57^{* *}$ & III & $5.89^{* * * *}$, & III & $4.06^{* * *}$, & III \\
\hline $\mathrm{Fa} / \mathrm{Fi}$ & $7.91^{* * *}$ & $\mathrm{~V}$ & $4.49^{* * *}$ & $\mathrm{~V}$ & $10.04^{* * *}$ & $\mathrm{~V}$ & $11.18^{* * *}$ & V \\
\hline Interval & $1.99^{\mathrm{NS}}$ & & $0.86^{\mathrm{NS}}$ & & $1.06^{\mathrm{NS}}$ & & - & \\
\hline
\end{tabular}

Numbers and asterisks in the cells are $F$-values and significance levels (NS for $P>0.05$, for $P<0.05$, **for $P<0.01$, and ${ }^{* * *}$ for $P<0.001$ ). Roman numerals denote the type of variation pattern; I, difference between northern (Seoul and Daejeon) and southern (Daegu, Gwangju, Busan, Jeju, and Saga) localities; II, north-south distinction with Daegu being similar to northern localities; III, north-south distinction with Saga being similar to the northern localities including Daegu; IV, mainland-island variation with Jeju and Saga being different from each other; and V, Korea-Japan distinction.

NS, not significant; Da, Di, Dp, duration of anterior, inflection, and posterior parts; Fa, Fi, Fp, dominant frequencey of anterior, inflection, and posterior parts. 
respectively. Contributions of each variable to the PCs are shown in Table 2; PC1 was mostly composed of temporal traits, whereas PC2 and PC3 were mainly composed of frequency-related traits. PC1 was higher in northern
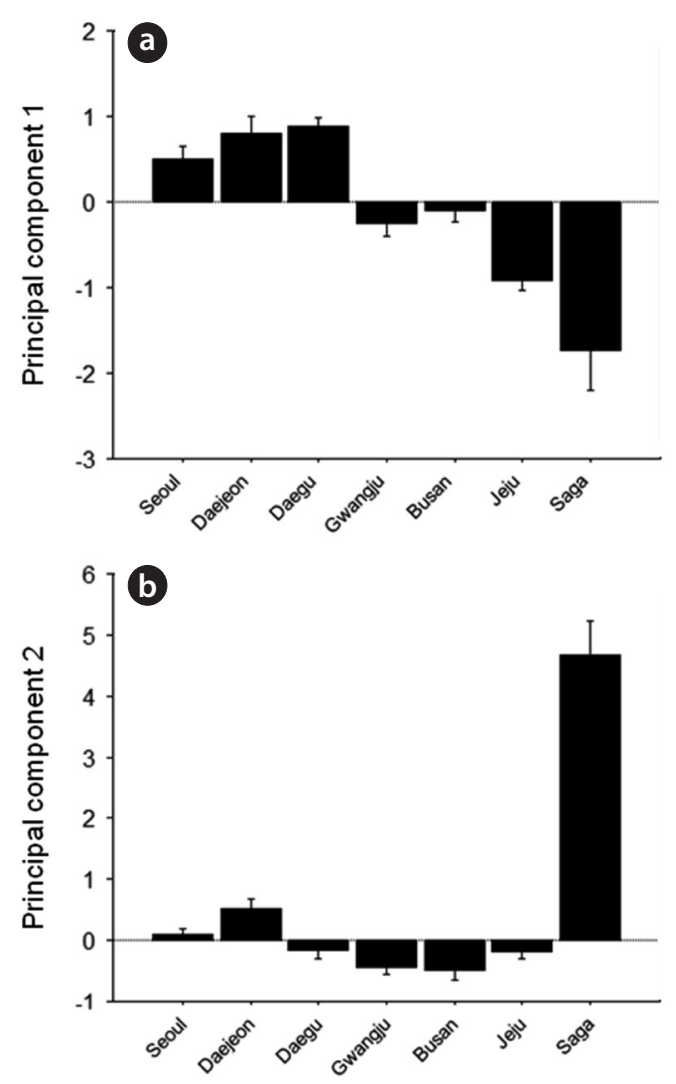

Fig. 4. Geographic variation in the principal components for vocal traits. Principal component 1 (a) and 2 (b) explained $29.2 \%$ and $26.8 \%$ of the variance, respectively.

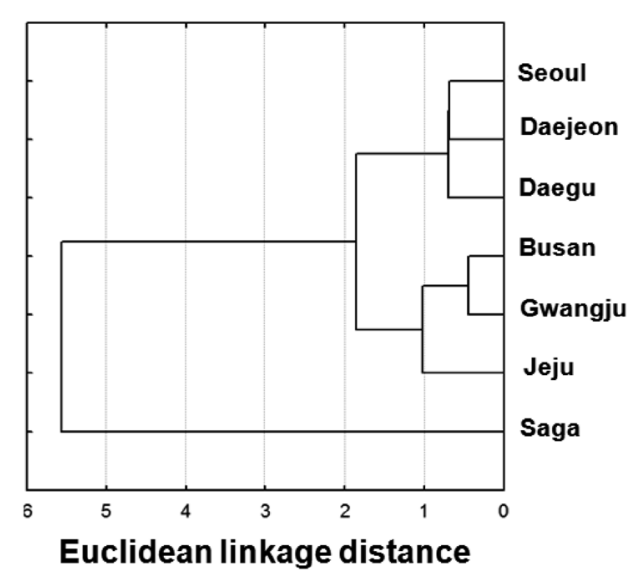

Fig. 5. The results from a cluster analysis based on the least square means of factor scores from principal components analyses.
Korean localities (Seoul, Daejeon, and Daegu); PC2 was slightly lower in southern Korean localities but it was the highest on Saga (Fig. 4). PC1 showed a pattern of geographic variation that was similar to category II and PC2 to category IV (Fig. 4). PC3 showed a similar pattern as PC1 (data not shown).

Cluster analyses based on the PCs (Fig. 5) clearly showed divergence between the calls of island localities and those of mainland localities. Among the mainland localities, a north (Seoul, Daejeon, and Daegu)-south (Gwangju and Busan) distinction was observed.

\section{DISCUSSION}

We found two main patterns of geographic variation in the chatter calls of black-billed magpies in Korea and Japan; Korean-Japanese differentiation and a northsouth differentiation among Korean localities. The former clearly showed the role of the sea for promoting vocal differentiation in magpies. The level of differentiation depended on time since the geographic isolation of the population on Saga, which was isolated from the mainland populations about 400 years ago, were more differentiated from mainland populations than those of magpies on Jeju, which has been isolated for 21 years. Twenty-one years, which corresponds to two to three generations of magpies, is not sufficient to produce clear differentiation in call characteristics from the source populations.

Japanese magpies showed a very distinct call structure. Their calls consisted of a shorter anterior part, an inflection part with lower frequency, and a longer posterior

Table 2. Factor loading of the variables

\begin{tabular}{lccc}
\hline & Prin1 & Prin2 & Prin3 \\
\hline $\mathrm{Da}$ & $\underline{0.49}$ & -0.08 & -0.06 \\
$\mathrm{Di}$ & -0.01 & -0.24 & 0.10 \\
$\mathrm{Dp}$ & $\underline{-0.47}$ & 0.30 & 0.13 \\
$\mathrm{Di} / \mathrm{Da}$ & $\underline{-0.58}$ & 0.29 & 0.11 \\
$\mathrm{Fa}$ & 0.25 & $\underline{0.44}$ & $\underline{0.45}$ \\
$\mathrm{Fi}$ & 0.31 & 0.26 & $\underline{0.44}$ \\
$\mathrm{Fp}$ & -0.08 & -0.36 & $\underline{0.73}$ \\
$\mathrm{Fa} / \mathrm{Fi}$ & 0.20 & $\underline{0.61}$ & -0.16 \\
\hline
\end{tabular}

High contributions of vocal variables are underlined and were used to interpret the principal components.

$\mathrm{Da}$, Di, Dp, duration of anterior, inflection, and posterior parts; $\mathrm{Fa}, \mathrm{Fi}, \mathrm{Fp}$, dominant frequencey of anterior, inflection, and posterior parts. 
part than those of Korean magpies. Although the importance and function of each part in a magpie vocal signal are unknown, our results suggest that the inflection and posterior parts contain information that should be delivered over longer distances. The inflection part was short but the energy was much more concentrated on the main tone than on the anterior and posterior parts. Furthermore, the posterior part was produced with greater energy in general than the anterior part, which was reflected in the darker sonogram, both in the main tone and harmonics (Fig. 2). The population density of magpies on Saga is far lower than that of mainland populations (Lee personal observation, Eguchi personal communication). Hence, the chatter calls of Japanese magpies must be carried over longer distances. Calls that contain parts with low frequencies and a long duration may be attenuated less as they travel over long distances, and Japanese magpies develop these types of calls to deliver messages efficiently over long distances.

Unlike our prediction, the effect of mountain ranges on the differentiation in vocal signals seemed to be minimal among the Korean magpie populations. The northsouth differentiation among Korean localities was not congruent with the predictions made based on the presence of main mountain ranges. For example, if the main mountain ridges (Baekdudaegan; the thick solid line in Fig. 1) serve as a geographic barrier for magpie dispersal and cause vocal differentiation, we would expect that Seoul and Daejeon would form one cluster and Daegu and Busan would form the other. Although some call traits did show this pattern (marked as 'I' in Table 1), the most prevalent pattern was the northern cluster being composed of Seoul, Daejeon, and Daegu and the southern cluster being composed of the rest (except for Saga). The observation that the call structure of Daegu magpies was similar to that of Seoul and Daejeon magpies does not support the hypothesis that vocal differentiation depended on the mountain ridge.

Call structure is influenced by habitat type (Date and Lemon 1993, Tubaro and Segura 1995); species or populations inhabiting thick, dense forests often have vocalizations with lower frequencies than related species or populations in open areas to increase the efficiency of call delivery through vegetation (Wiley and Richards 1982). In our study, the recordings were conducted in similar environments to minimize the effect of habitat on the results. In all localities, except for Saga, magpies were distributed in similar densities in half-urbanized environments. Thus, we excluded the possibility that the pattern of vocal differentiation among the Korean locali- ties was related to the habitat difference.

As our recording dates coincided with the magpie breeding season, the hormonal status of individuals may have influenced their call structures. For example, females may produce higher pitched calls around the time of egg-laying. If some localities were recorded around similar breeding stages, the calls from these localities may appear more similar to each other than to other localities. Currently, we do not have direct evidence to examine the effect of hormonal status on vocal signals. If we had some data on the average egg laying date for each population, it would be possible to test or at least control such an effect statistically.

Calls are often used for individual recognition (Falls 1982), and inter-individual variations in call structure may be indicative of the selective pressure for individual recognition. Thus, it is possible that the vocal variations observed in our study may have accrued from different levels of individual variation among the localities. If a high density of individuals necessitates a fine-tuned mechanism for individual recognition based on vocal signals and increases inter-individual variation in vocal signals, one could predict that the localities with a higher density of individuals would show greater levels of interindividual variation in vocal signals. However, if a difference in the level of inter-individual variation is the only factor for vocal variation in the magpies in our study, there is no a priori reason to expect similarity among the localities. Thus, it is less likely that the vocal signal geographic variation patterns of magpies that we observed are due to any potential confounding effect of vocal signals functioning for individual recognition.

Because the pattern of geographic variation in vocal signals of magpies in South Korea cannot be readily explained by mountain ranges or habitat structure, we hypothesize that the patterns of geographic variation in the structure of magpie chatter calls for magpies residing in South Korea might have been shaped by a sudden expansion of magpies followed by low level of local isolation, which may have lead to vocal differentiation. Currently, three studies have attempted to reveal the genetic structure of the magpie populations in South Korea and Japan. Based on random amplified polymorphic DNA methods on nuclear DNA (Eo et al. 2002), populations in the eastern region of the main mountain range appear to be genetically more similar to the Saga population than to the western population of the Korean peninsula. However, according to other studies using mtDNA (Jang 2004) and microsatellite DNA (Lee unpublished data), magpies residing in South Korea do not seem to have clear genetic 
differentiation. If the magpies on the Korean peninsula went through a very rapid expansion, clear patterns of genetic differentiation may not be observed. If local isolation, which may lead to vocal differentiation, had occurred after this rapid population expansion, the pattern of vocal differentiation would be patchy and may not be highly correlated with the presence of a geographic barrier. Similar results were obtained in morphological variation studies of local Korean black-billed magpie populations (Lee 2006). Lee (2006) found significant differences in morphological characteristics among the local populations, the pattern of which was not related to the existence of putative geographic barriers but could be explained as adaptations to local conditions. Unlike morphological characteristics, for which potential functional values of variations can be easily identified (e.g., thicker pectoral muscle in windy areas for efficient maneuvers), the functional value of vocal variants can only be associated with local environmental conditions only after the "vocal environment" is clearly defined. The vocal environment can be defined as the environmental conditions that render certain types of calls more preferable, and it may not be associated with the geographic location (such as the proximity to high mountain ranges) of the sampling site. For example, higher-pitched calls might be more efficiently delivered in environments with higher levels of noise (Slabbekoorn and Peet 2003, Bermúdez-Cuamatzin et al. 2010). In our study, if the selective pressures from the "vocal environment" (that are not associated with geographic locations) differed among localities, the vocal features that are preferred among localities should be different, and this might have caused vocal differentiation that is not related to the geographic barrier location. Thus, understanding the vocal environment is crucial to assess the functional value of vocal variants and to further understand the pattern of vocal variation in the population. Along with elucidating the vocal environment of Korean magpie populations, more extensive sampling is needed to clarify the functional aspects of geographic variation in vocal signals of Korean magpies.

\section{ACKNOWLEDGMENTS}

We are grateful to Dr. Kazuhiro Eguchi for helping us to record vocalizations of Japanese magpies. We thank the magpie team members for constructive comments and help throughout the study. This work was funded by the Long-term Ecological Monitoring Program on Animal
Populations from the Korean Ministry of Environment, Research Grant of 2007 from Ewha Womans University, National Research Foundation Grant No. KRF-20100029613, NRF-2010-K001149, NRF-2010-0009006 and the Brain Korean 21 Project .

\section{LITERATURE CITED}

Baker MC, Logue DM. 2003. Population differentiation in a complex bird sound: a comparison of three bioacoustical analysis procedures. Ethology 109: 223-242.

Bermúdez-Cuamatzin E, Ríos-Chelén AA, Gil D, Garcia CM. 2010. Experimental evidence for real-time song frequency shift in response to urban noise in a passerine bird. Biol Lett 7: 36-38.

Birkhead TR. 1991. The Magpies: The Ecology and Behaviour of Black-billed and Yellow-billed Magpies. T\&AD Poyser, London.

Bradbury JW, Cortopassi KA, Clemmons JR. 2001. Geographical variation in the contact calls of Orange-fronted Parakeets. Auk 118: 958-972.

Chappell J, Kacelnik A. 2002. Tool selectivity in a non-primate, the New Caledonian crow (Corvus moneduloides). Anim Cogn 5: 71-78.

Date EM, Lemon RE. 1993. Sound transmission: a basis for dialects in birdsong? Behaviour 124: 291-312.

Eguchi K, Kubo H. 1992. The origin of the Magpie Pica pica sericea in Japan: an investigation of historical records. J Yamashina Inst Ornithol 24: 32-39. (in Japanese with English abstract)

Emery NJ, Clayton NS. 2004. The mentality of crows: convergent evolution of intelligence in corvids and apes. Science 306: 1903-1907.

Enggist-Dueblin P, Pfister U. 2002. Cultural transmission of vocalizations in Ravens, Corvus corax. Anim Behav 64: 831-841.

Eo SH, Hyun JO, Lee WS, Choi TB, Rhim SJ, Eguchi K. 2002. Effects of topography on dispersal of black-billed magpie Pica pica sericea revealed by population genetic analysis. J Ethol 20: 43-47.

Falls JB. 1982. Individual recognition by sounds in birds. In: Acoustic Communication in Birds. Vol. 2 (Kroodsma DE, Miller EH, eds). Academic Press, New York, NY, pp 237278.

Goodwin D. 1986. Crows of the World. $2^{\text {nd }}$ ed. British Museum of Natural History, London.

Hunt GR, Gray RD. 2003. Diversification and cumulative evolution in New Caledonian crow tool manufacture. Proc R Soc Lond B 270: 867-874. 
Jang H. 2004. Genetic differentiation of Korean black-billed magpies (Pica pica sericea Gould). MS Thesis. Seoul National University, Seoul, Korea.

Jarvis ED. 2004. Learned birdsong and the neurobiology of human language. Ann N Y Acad Sci 1016: 749-777.

Kim YP, Yim ES, Kim YJ. 2004. Restructuring Mountain Systems in Korean Peninsula: Focusing on Mountain Range Analysis. Korea Research Institute for Human Settlements, Anyang.

Kleeman PM, Gilardi JD. 2005. Geographical variation of St. Lucia Parrot flight vocalizations. Condor 107: 62-68.

Koo TH. 1994. Restoration and status of released Magpie, Pica pica sericea Gould in Chejudo. Nat Conserv 88: 27 29. (in Korean)

Krebs JR, Kroodsma DE. 1980. Repertoires and geographical variation in bird song. Adv Stud Behav 11: 143-177.

Kroodsma D. 2005. The Singing Life of Birds: The Art and Science of Listening to Birdsong. Houghton Mifflin Company, Boston and New York.

Laiolo P, Rolando A. 2003. The evolution of vocalisations in the genus Corvus: effects of phylogeny, morphology and habitat. Evol Ecol 17: 111-123.

Laland KN, Janik VM. 2006. The animal cultures debate. Trends Ecol Evol 21: 542-547

Lee J. 2006. Morphological variations in regional population of black-billed magpies in South Korea. MS Thesis.
Seoul National University, Seoul, Korea.

MacDougall-Shackleton EA, MacDougall-Shackleton SA. 2001. Cultural and genetic evolution in mountain whitecrowned sparrows: song dialects are associated with population structure. Evolution 55: 2568-2575.

Marler P, Tamura M. 1964. Culturally transmitted patterns of vocal behavior in sparrows. Science 146: 1483-1486.

Slabbekoorn H, Peet M. 2003. Ecology: birds sing at higher pitch in urban noise. Nature 426: 267.

Tubaro PL, Segura ET. 1995. Geographic, ecological and subspecific variation in the song of the rufous-browed peppershrike (Cyclarhis gujanensis). Condor 97: 792-803.

Tubaro PL, Segura ET, Handford P. 1993. Geographic variation in the song of the Rufous-collared Sparrow in Eastern Argentina. Condor 95: 588-595.

Webber T, Stefani RA. 1990. Evidence for vocal learning by a scrub jay. Auk 107: 202-204.

Wiley RH, Richards DG. 1982. Adaptations for acoustic communication in birds: sound transmission and signal detection. In: Acoustic Communication in Birds. Vol. 1. (Kroodsma DE, Miller EH, eds). Academic Press, New York, NY, pp 132-181.

Wright TF, Wilkinson GS. 2001. Population genetic structure and vocal dialects in an Amazon Parrot. Proc R Soc Lond B 268: 609-616. 